\title{
Radioiodine treatment of hyperthyroidism: fixed or calculated doses; intelligent design or science?
}

\author{
Johannes W. van Isselt • John M. H. de Klerk • \\ Cornelis J. M. Lips
}

Published online: 14 September 2007

(C) Springer-Verlag 2007

\section{Dear Sir,}

In the ongoing debate about the optimal treatment of hyperthyroidism with radioiodine, Sisson et al. advocate a dose strategy, which is supported only in part by the authors' arguments [1].

The development of hypothyroidism after the elimination of hyperthyroidism, inevitable as it may be, does not per se necessitate the acceleration of this outcome. Even though death is an inevitable consequence of life, we strive to delay this outcome as long as we possibly can. The incidence of hypothyroidism is about $3-5 \%$ per annum; thus, if a euthyroid state can be achieved, it may be maintained for about 15 years on average. Normal thyroid function provides a physiologic hormonal balance, adaptive to changes in metabolic and psychological states. Euthyroidism has been defined as the preferred treatment outcome in the Dutch conjoint evidence-based guideline on thyroid disorders [2]. Patients suffering from a recurrence of hyperthyroidism after treatment are usually kept on antithyroid drug (ATD) medication until a definitive cure has been achieved. As with this approach, there is no pro-

\footnotetext{
J. W. van Isselt $(\bowtie)$

Department of Radiology and Nuclear Medicine E02.222,

University Medical Center Utrecht,

P.O. Box 85500, 35008 GA Utrecht, The Netherlands

e-mail: J.W.vanIsselt@umcutrecht.nl

J. M. H. de Klerk

Department of Radiology and Nuclear Medicine,

Meander Medical Center,

Amersfoort, The Netherlands

C. J. M. Lips

Department of Endocrinology, University Medical Center Utrecht, Utrecht, The Netherlands
}

longation of clinically overt hyperthyroidism and the associated risks are non-existent.

As pointed out by Sisson et al., radiation safety issues are not always respected. Indeed, the as low as reasonably achievable (ALARA) principle must not be ignored, least of all when detrimental effects are the expressed goal of the radionuclide application. In the aforementioned guideline, the ALARA principle has in fact been recognised as the single most compelling argument for choosing ATD treatment rather than radioiodine as the primary therapy option for patients with Graves' hyperthyroidism [2]. A vast majority of European and Japanese physicians are inclined to give the patient this chance to have a spontaneous remission, thereby avoiding lifelong treatment with thyroxine [3]. Apparently, not all physicians agree that 'the disorder should be eliminated as soon as possible' when this involves an increased likelihood of early hypothyroidism.

When radioiodine is applied only to patients failing ATD treatment, the overall radiation burden from this modality is reduced by $30-50 \%$ (i.e. the cure rate after ATD treatment). ALARA applies to patients, workers and members of the society alike. It is not self-evident how the radioiodine treatment goal can be achieved with the lowest radiation burden to all involved. In one study with a fixed dose of $370 \mathrm{MBq}$, about two-thirds of all patients were over-treated [4]. In another randomised, prospective study comparing 60 and 90 Gy target doses, the mean cumulative dose to achieve euthyroidism was $337 \mathrm{MBq}$ [5]. Effectively, any dose regimen will result in a number of patients receiving amounts of radioiodine exceeding the dose required to cure hyperthyroidism. However, with an individually calculated dose, the extra radiation burden caused by additional treatments should be weighed against the reduced number of hypothyroid outcomes. 
Sisson et al. address a number of variables with prognostic impact on the radioiodine therapy outcome. In their discourse, they do not stipulate what 'adjustments for the effects of known factors' could be made. In patients with Graves' hyperthyroidism, the radioiodine dose-effect relationship is largely influenced by such factors as thyroid volume and radioiodine turnover rate $[6,7]$. The recommendation by Sisson et al. to measure the thyroid volume and the radioiodine uptake concurs with the view of many physicians. Whereas the authors do mention the inferiority of thyroid volume measurement by palpation, the same should be said for the very popular scintigraphic method, which harbours a mean error of about $30 \%$ [8, 9]. Radioiodine uptake measurements are another pitfall, as they show large variations over time in patients with Graves' hyperthyroidism [10]. Consequently, uptake values may not contribute to more accurate radioiodine treatment doses unless they are performed immediately before radioiodine treatment. Moreover, a single measurement does not provide information about the radioiodine turnover rate, which bears directly on the thyroid absorbed dose [7, 11], and thus has a strong influence on the incidence of hypothyroidism after radioiodine treatment [12]. The authors' statement concerning the relative consistency of the effective half-life of radioiodine is debatable - at least for patients with Graves' hyperthyroidism, in whom differences in disease activity produce great differences in thyroidal iodine metabolism [10].

Proposals to dismiss radioiodine treatment strategies aiming at euthyroidism are premature. Whereas a number of therapeutically prognostic variables have been identified over the years, few are actually being applied in clinical practice. The consequent application of this scientific evidence will increase the probability of cure and may help resolve an issue that has been elusive for over six decades.

\section{References}

1. Sisson JC, Avram AM, Rubello D, Gross MD. Radioiodine treatment of hyperthyroidism: fixed or calculated doses; intelligent design or science? Eur J Nucl Med Mol Imaging 2007;34:112930.

2. Anonymous. Richtlijn Schildklierfunctiestoornissen [in Dutch] http://www.internisten.nl/files/richtlijnschildklierfunctiestoornis sendefinitiefmei2007.pdf

3. Wartofsky L, Glinoer D, Solomon B, Nagataki S, Lagasse R, Nagayama Y, Izumi M. Differences and similarities in the diagnosis and treatment of Graves'disease in Europe, Japan, and the United States. Thyroid 1991;1:129-35.

4. Allahabadia A, Daykin J, Sheppard MC, Gouch SCL, Franklyn JA. Radioiodine treatment of hyperthyroidism - prognostic factors for outcome. J Clin Endocrinol Metab 2001;86:3611-7.

5. Howarth D, Epstein M, Lan L, Tan P, Booker J. Determination of the optimal minimum radioiodine dose in patients with Graves' disease: a clinical outcome study. Eur J Nucl Med 2001;28:148995.

6. DeGroot LJ, Stanbury JB. Graves' disease: diagnosis and treatment. In: DeGroot LJ, Stanbury JB, editors. The thyroid and its diseases, 4th edn. New York: Wiley; 1975. p. 314-67.

7. Aktay R, Rezai K, Seabold JE, Bar RS, Kirchner PT. Four- to twenty-four-hour uptake ratio: an index of rapid iodine-131 turnover in hyperthyroidism. J Nucl Med 1996;37:1815-9.

8. Himanka E, Larsson L. Estimation of thyroid volume. Acta Radiol $1955 ; 43: 125-31$.

9. van Isselt JW, Beekman FJ, Kamphuis C, de Klerk JMH, Polman LJ, van Gils APG, Vincken K, van Rijk PP. Comparison of methods for thyroid volume estimation in patients with Graves' disease. Eur J Nucl Med Mol Imaging 2003;30:525-31.

10. van Isselt JW, de Klerk JMH, Koppeschaar HPF, van Rijk PP. Iodine-131 uptake and turnover rate vary over short intervals in Graves' disease. Nucl Med Commun 2000;21:609-16.

11. Berg GEB, Michanek AMK, Holmberg ECV, Fink M. Iodine-131 treatment of hyperthyroidism: significance of effective half-life measurements. J Nucl Med 1996;37:228-32.

12. Grosso M, Traino A, Boni G, Banti E, Della Porta M, Manca G, et al. Comparison of different thyroid committed doses in radioiodine therapy for Graves' hyperthyroidism. Cancer Biother Radiopharm 2005;20:218-23. 